\title{
Efficacy of Rituximab for Refractory Pyoderma Gangrenosum-Like Ulcers in Granulomatosis With Polyangiitis Associated to Antiphospholipid Antibodies
}

\author{
Julia RIERA®, Jorge MUSURUANA®, Cecilia COSTA®i], Javier CAVALLASCA® \\ Hospital JB Iturraspe, Rheumatology and Autoimmune Diseases, Santa Fe, Argentina
}

\begin{abstract}
Pyoderma gangrenosum (PG) is a neutrophilic dermatosis that most often presents with painful ulcerations of violaceous borders in lower limbs and/or trunk. PG treatment varies according to the severity of the lesion and may either respond to local therapies or require immunosuppressive agents. In this article, we present the case of an antiphospholipid antibody-positive 59-year-old female patient diagnosed with granulomatosis with polyangiitis who developed severe PG-like skin involvement that was responsive to rituximab therapy.

Keywords: Antiphospholipid antibodies, granulomatosis with polyangiitis, pyoderma gangrenosum, rituximab.
\end{abstract}

Systemic autoimmune diseases are characterized by a wide variety of clinical manifestations, including cutaneous lesions. Pyoderma gangrenosum (PG) and pyodermalike lesions can be associated with different rheumatic conditions, such as granulomatosis with polyangiitis (GPA). ${ }^{1}$

Management of this pathology is based on local wound care, avoidance of trauma, and in some occasions, systemic therapy with systemic corticosteroids and cyclosporine being the mainstays of treatment. In recalcitrant PG, biologic medications, such as tumor necrosis factor-alpha (TNF- $\alpha$ ) inhibitors, could be necessary. Actually, infliximab (IFX) is the only biologic that has shown efficacy in classic PG in a randomized, double-blind, controlled trial (level 1 evidence). ${ }^{2}$
Rituximab (RTX) was approved for use in GPA by the Food and Drug Administration in April 2011. The use of RTX for cutaneous and subcutaneous GPA lesions has previously been reported in some case series and case reports. ${ }^{3}$

In this article, we present the case of an antiphospholipid antibody (aPL)-positive female patient diagnosed with GPA who developed severe PG-like skin involvement that was responsive to RTX therapy.

\section{CASE REPORT}

In 2003, a 59-year-old female patient was referred to the Rheumatology Division after developing symmetric polyarthritis of small and

Received: March 15, 2019 Accepted: August 14, 2019 Published online: January 08, 2020

Correspondence: Javier Cavallasca, MD. Sección Reumatología y Enfermedades Autoinmunes Sistémicas. Hospital JB Iturraspe. Bv. Pellegrini 3551. CP 3000. Santa Fe. Argentina. Tel: 03424575757 e-mail: jcavallasca@yahoo.com.ar

Riera J, Musuruana J, Costa C, Cavallasca J. Efficacy of Rituximab for Refractory Pyoderma Gangrenosum-Like Ulcers in Granulomatosis With Polyangiitis Associated to Antiphospholipid Antibodies. Arch Rheumatol 2020;35(3):449-453. 
large joints and a solitary pulmonary nodule. She denied Raynaud's phenomenon, xerophtalmia, xerostomia and alopecia. Her obstetric history included a spontaneous abortion in the first trimester of pregnancy. A written informed consent was obtained from a relative of the patient.

Upon examination, she was afebrile and her blood pressure was normal. Joint examination revealed 12 tender joints and 13 swollen joints, involving wrists, metacarpophalangeal, proximal interphalangeal, knees and ankle joints. Pulmonary, cardiovascular, abdominal, dermatological and neurological examinations were not remarkable.

The histologic findings from lung biopsy were compatible with rheumatoid nodule without vasculitis. Complete blood count; levels of serum electrolytes, glucose, bilirubin, and protein; and liver- and renal-function tests were normal except for an erythrocyte sedimentation rate of $82 \mathrm{~mm} /$ hour (Westergren method). Rheumatoid factor (latex), Rosse Ragan, antinuclear antibody human epithelial type 2, anti-double stranded deoxyribonucleic acid, anti-Ro/SSA and anti$\mathrm{La} / \mathrm{SSB}$ were negative. Serum complement levels were normal. Determination of anti-cyclic citrullinated peptide (anti-CCP) antibodies was not available in our institution at that time. With a presumptive diagnosis of seronegative rheumatoid arthritis, hydroxychloroquine $400 \mathrm{mg} /$ day and prednisone $10 \mathrm{mg} /$ day were started. Due to pulmonary involvement, methotrexate (MTX) was not contemplated.

Two months later, the patient developed digital ischemic lesions in her hands with necrosis in the first phalange of her third left finger that led to autoamputation. Lupus anticoagulant (LAC) was positive and anticardiolipin antibodies (ACAs) IgG $20 \mathrm{UGPL} / \mathrm{mL}$ and IgM $25 \mathrm{UMPL} / \mathrm{mL}$ (low title) were also positive. Anticoagulation with acenocoumarol was started. An angiography of upper limbs was not performed.

In the following three years, she progressively developed distal sensory-motor polyneuropathy, left ptosis associated with third cranial nerve palsy, sinusitis, bloody rhinorrhea, and livedo reticularis in lower limbs with petechiae progressing to small necrotic ulcerations. Leflunomide was added to previous treatment.
New laboratory tests showed positive antineutrophil cytoplasmic antibody (c-ANCA): 1/80, anti-proteinase 3 antibodies (anti-PR3) $46.5 \mathrm{U} / \mathrm{mL}$ (positive $\geq 3.5 \mathrm{U} / \mathrm{mL}$ ) and negative anti-CCP antibodies.

Based on the 1990 American College of Rheumatology criteria (nasal and pulmonary compromise, besides c-ANCA and anti-PR3 +) a diagnosis of GPA was established. ${ }^{4}$ Treatment with intravenous methylprednisolone $(1 \mathrm{~g} /$ day for three days) was initiated, followed by oral prednisone in tapering doses and monthly intravenous cyclophosphamide $1 \mathrm{~g} / \mathrm{m}^{2}$ for 12 consecutive months.

In May 2007, the patient developed painful ulcers in her right leg with the subsequent formation of a large necrotic eschar. An escharotomy was performed and its anatomopathological findings showed thrombosis and leukocytoclastic vasculitis (Figure 1).

Between June and July 2007, anticoagulation was stopped due to lower gastrointestinal bleeding (angiography not performed) and pulmonary hemorrhage; intravenous gammaglobulin (IVIG) was administered.

Cyclophosphamide was restarted for a six-month period, with prednisone in tapering doses. Since there was no renal involvement and due to the severity of the arthritis, leflunomide $20 \mathrm{mg} / \mathrm{day}$, and MTX $15 \mathrm{mg} /$ week were added. Anticoagulation with acenocoumarol was also restarted.

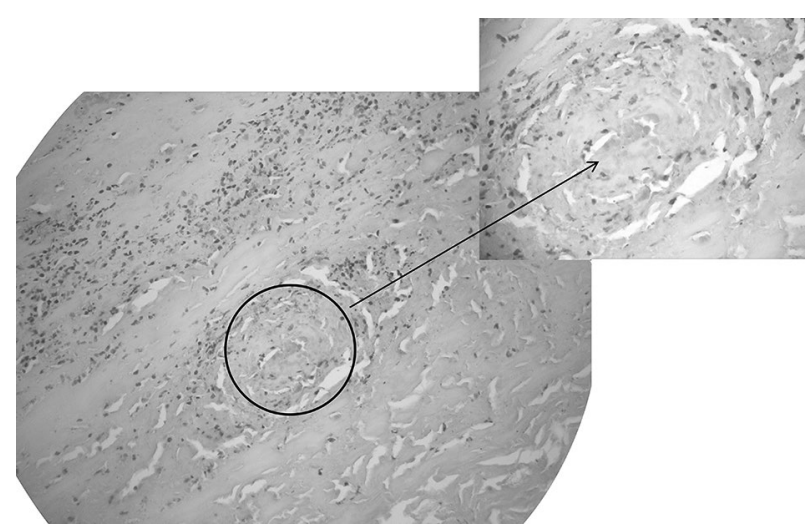

Figure 1. Light microscopic examination of ulcer showing thrombosis (circle and arrow) and leukocytoclastic vasculitis (H-E ×200). 

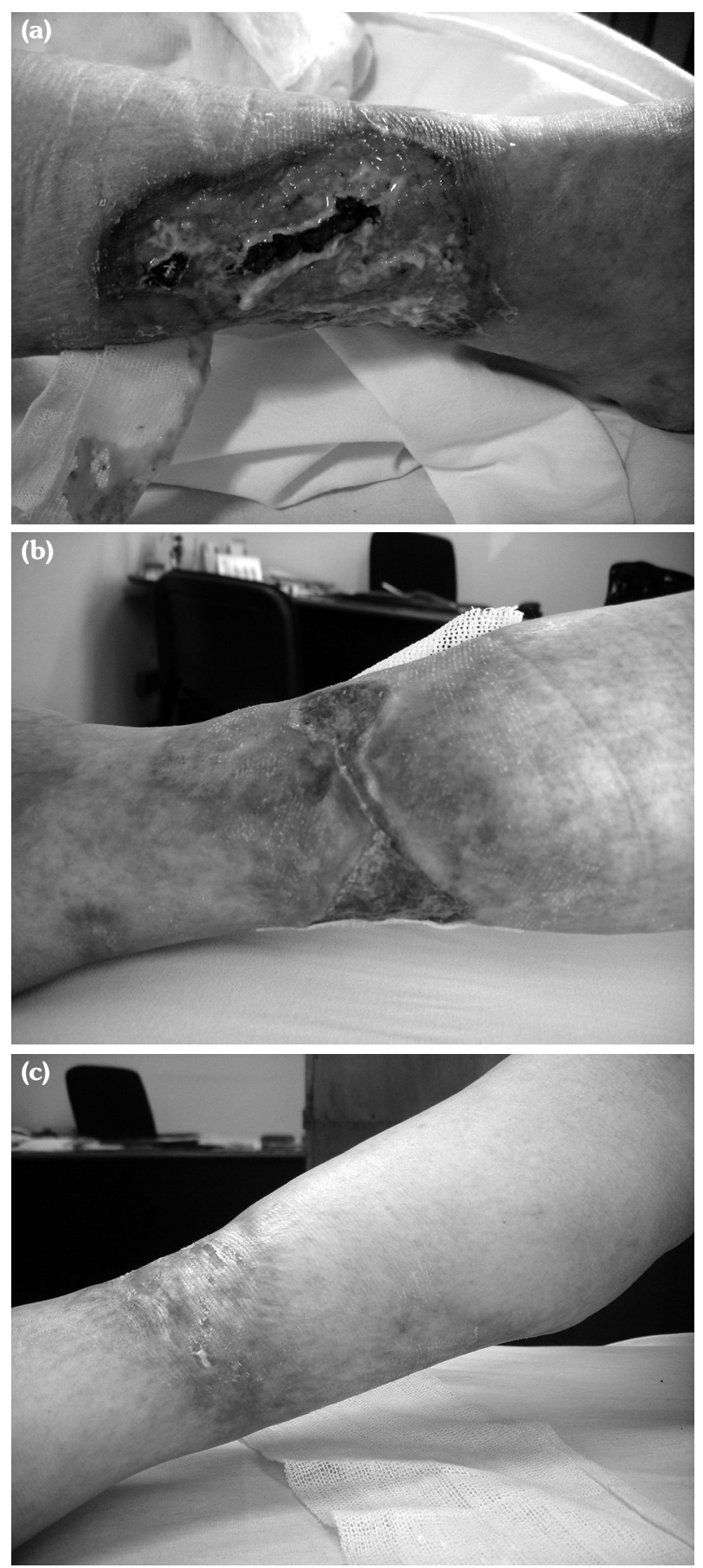

Figure 2. Pyoderma like-ulcers prior to initiation of (a), during (b) and after treatment with rituximab (c).

In February 2009, due to extended skin lesions and necrosis, and considering two possible pathogenic mechanisms; vasculitis and thrombosis secondary to APLs, intravenous RTX $375 \mathrm{mg} / \mathrm{m}^{2}$ (750 mg) was initiated once a week for four weeks with successful response
(Figures 2a-c). Two months after the last infusion, improvements in the skin lesions were seen.

In November of the same year, coinciding with the appearance of new skin lesions, exophthalmia secondary to a right-sided retroorbital pseudotumor developed. In order to cover both clinical manifestations, another infusion of RTX was administered with neurological and cutaneous improvement.

The patient continued maintenance treatment with azathioprine (AZA) $200 \mathrm{mg} /$ day, prednisone $7.5 \mathrm{mg} / \mathrm{day}$, and infusions of RTX every six months with successful response until September 2013, when she became lost to follow-up.

In December 2014, after discontinuing all types of treatment, she came to the office presenting with severe renal failure. Soon after, the patient died due to complications associated with this condition.

\section{DISCUSSION}

Granulomatosis with polyangiitis is a rare systemic disease characterized by vasculitis and necrotizing granulomatous inflammation that usually affects the respiratory tract, kidneys and eyes. Less frequently, articular and cutaneous involvement is seen. ${ }^{1}$

Initially, our patient suffered polyarthritis indistinguishable from rheumatoid arthritis. However, during the course of her illness, she developed other clinical features (involvement of the respiratory tract and nervous system) that, along with positive serology tests for ANCA and anti-PR3, helped to diagnose GPA.

The prevalence of $\mathrm{aPL}$ has been reported in $17 \%$ of patients with systemic vasculitis. ${ }^{5}$ Recently, LAC presence was associated with a higher vasculitis damage index in patients with ANCA-associated vasculitis. ${ }^{6}$

Granulomatosis with polyangiitis in particular, has an increased risk of thromboembolism, particularly during periods of activity. ${ }^{7}$ The presence of vasculitis and thrombosis in the ulcerations allowed us to arrive at a diagnosis of vasculitis and probable antiphospholipid syndrome (APS) despite the not repeated LAC or ACA tests. Indefinite anticoagulation was 
Table 1. RTX efficacy in PG-like ulcers associated to granulomatosis with polyangiitis

\begin{tabular}{|c|c|c|c|c|c|}
\hline & Age/sex & Clinical findings of GPA & $\begin{array}{l}\text { Location of } \\
\text { ulcers }\end{array}$ & $\begin{array}{l}\text { Positive laboratory } \\
\text { findings }\end{array}$ & Therapy \\
\hline Kindle S and Fanciullo ${ }^{12}$ & $52 / \mathrm{F}$ & $\begin{array}{l}\text { Rhinitis, sinusitis, } \\
\text { epistaxis, pulmonary } \\
\text { nodules. }\end{array}$ & Legs & ANCA, PR3 & CS, RTX \\
\hline Murthy RK et al. ${ }^{13}$ & $50 / \mathrm{M}$ & Pulmonary cavities & $\begin{array}{l}\text { Legs, arms, scalp, } \\
\text { penis, back. }\end{array}$ & $\begin{array}{l}\text { ANCA, PR3, ESR, } \\
\text { CRP, hematuria }\end{array}$ & CS, RTX \\
\hline Sen $\mathrm{M}$ et $\mathrm{al}^{3}{ }^{3}$ & $29 / F$ & & Legs & ANCA, PR3, & $\begin{array}{c}\text { CS, MTX, CYC, } \\
\text { MM, RTX }\end{array}$ \\
\hline Tashtoush B et al. ${ }^{1}$ & $52 / \mathrm{M}$ & $\begin{array}{l}\text { Rhinorrhea, epistaxis, } \\
\text { perforation of the nasal } \\
\text { septum, pulmonary } \\
\text { cavities. }\end{array}$ & $\begin{array}{c}\text { Arms, back, face } \\
\text { abdomen. }\end{array}$ & ANCA, PR3, & $\begin{array}{c}\text { CYC, CS, MTX, } \\
\text { RTX }\end{array}$ \\
\hline Donmez S et al. ${ }^{9}$ & $33 / \mathrm{F}$ & $\begin{array}{l}\text { Orbital involvement, oral } \\
\text { and esophageal ulcers, } \\
\text { cutaneous vasculitis, } \\
\text { alveolar hemorrhage. }\end{array}$ & Legs & $\begin{array}{c}\text { ANCA, PR3, } \\
\text { hematuria, RF, ESR, } \\
\text { anemia }\end{array}$ & $\begin{array}{l}\text { CS, CYC, AZA, } \\
\text { IFX, RTX }\end{array}$ \\
\hline Our patient & $59 / \mathrm{F}$ & $\begin{array}{l}\text { Compromise of upper } \\
\text { respiratory tract and } \\
\text { nervous system. }\end{array}$ & Legs & ANCA, PR3 & $\begin{array}{l}\text { CS, CYC, MTX, } \\
\text { LEF IVIG, RTX }\end{array}$ \\
\hline
\end{tabular}

indicated by the hematology section, due to the increased risk of thrombosis.

Skin involvement is seen in almost half of the patients with GPA and this may be the presenting complaint in $10-25 \%$ of cases. ${ }^{3}$ The most common cutaneous manifestations are petechiae-purpura, ulcerations, papules, nodules, digital necrosis, and splinter hemorrhages. ${ }^{8}$

Pyoderma gangrenosum is a neutrophilic dermatosis that most often presents with painful ulcerations of violaceous borders in lower limbs and/or trunk. In half of the cases, there is an underlying condition. ${ }^{2}$ Pyoderma-like lesions occur in up to $27 \%$ of patients with GPA. ${ }^{3}$

On the other hand, livedo reticularis is the most common dermatologic manifestation of APS. ${ }^{7}$ Our patient presented with livedo reticularis that progressed to necrotic ulcers.

The pathophysiology of PG remains poorly understood, though it is now believed to involve loss of innate immune regulation and altered neutrophil chemotaxis. Emerging evidence of the clinical efficacy of TNF- $\alpha$ inhibitor therapy for the treatment of PG strongly suggests a key role for this cytokine in the disease. ${ }^{2}$
Pyoderma gangrenosum treatment varies depending on the severity of the lesion and may either respond to local therapies or require immunosuppressive agents such as corticosteroids, MTX, AZA or mycophenolate mofetil.

Gammaglobulin and cyclophosphamide are also prescribed for refractory cases ${ }^{2}$ while biologic drugs such as IFX or RTX would be another option in these patients. ${ }^{9}$

On the other hand, RTX has demonstrated efficacy in cutaneous ulcers secondary to APS that were resistant to anticoagulation. ${ }^{10,11}$

Our patient received corticosteroids, cyclophosphamide, MTX, AZA, leflunomide and IVIG to treat the different manifestations of the disease. However, her cutaneous lesions only responded to RTX therapy. Other authors have reported similar findings with RTX in patients with PG or PG-like lesions who had responded unsuccessfully to corticosteroids ${ }^{12,13}$ and immunosuppressive agents (Table 1). ${ }^{1,3}$

In conclusion, this case shows that accurate diagnosis sometimes remains difficult, particularly in the presence of overlapping autoimmune diseases. This is when histopathological 
procedures become relevant. Additionally, this case report highlights the potential efficacy of RTX in patients with severe skin lesions due to ANCA-associated vasculitis unresponsive to conventional immunosuppressive therapy.

\section{Declaration of conflicting interests}

The authors declared no conflicts of interest with respect to the authorship and/or publication of this article.

\section{Funding}

The authors received no financial support for the research and/or authorship of this article.

\section{REFERENCES}

1. Tashtoush B, Memarpour R, Johnston Y, Ramirez J. Large pyoderma gangrenosum-like ulcers: a rare presentation of granulomatosis with polyangiitis. Case Rep Rheumatol 2014;2014:850364.

2. Ahronowitz I, Harp J, Shinkai K. Etiology and management of pyoderma gangrenosum: a comprehensive review. Am $J$ Clin Dermatol 2012;13:191-211.

3. Sen M, Dogra S, Rathi M, Sharma A. Successful treatment of large refractory pyoderma gangrenosumlike presentation of granulomatosis with polyangiitis by rituximab. Int $J$ Rheum Dis 2017;20:2200-2.

4. Jennette JC, Falk RJ, Bacon PA, Basu N, Cid MC, Ferrario F, et al. 2012 revised International Chapel Hill Consensus Conference Nomenclature of Vasculitides. Arthritis Rheum 2013;65:1-11.
5. Rees JD, Lança S, Marques PV, Gómez-Puerta $\mathrm{JA}$, Moco R, Oliveri $\mathrm{C}$, et al. Prevalence of the antiphospholipid syndrome in primary systemic vasculitis. Ann Rheum Dis 2006;65:109-11.

6. Jordan N, D'cruz DP. Association of lupus anticoagulant with long-term damage accrual in antineutrophil cytoplasmic antibody-associated vasculitis. Arthritis Care Res (Hoboken) 2016;68:711-5.

7. Lally L, Sammaritano LR. Vasculitis in antiphospholipid syndrome. Rheum Dis Clin North Am 2015;41:109-23.

8. de Cambourg G, Mahé A, Banea S, Moulinas C, Blaison G. Ganulomatosis with polyangiitis revealed by a cutaneous ulceration mimicking a pyoderma gangrenosum: Two patients. Rev Med Interne 2016;37:632-5.

9. Donmez S, Pamuk ON, Gedik M, A K R, Bulut G. A case of granulomatosis with polyangiitis and pyoderma gangrenosum successfully treated with infliximab and rituximab. Int J Rheum Dis 2014;17:471-5.

10. Tenedios F, Erkan D, Lockshin MD. Rituximab in the primary antiphospholipid syndrome (PAPS) Arthritis Rheum 2005;52:4078.

11. Erkan D, Vega J, Ramón G, Kozora E, Lockshin MD. A pilot open-label phase II trial of rituximab for noncriteria manifestations of antiphospholipid syndrome. Arthritis Rheum 2013;65:464-71.

12. Kindle S, Fanciullo J. Healing of leg ulcers associated with granulomatosis with polyangiitis (Wegener granulomatosis) after rituximab therapy. Cutis 2017;99:12-5.

13. Murthy RK, Jackson J, Chatham WW, Sami N. Extensive pyoderma gangrenosum associated with granulomatosis with polyangiitis with both responsive to rituximab. J Clin Rheumatol 2016;22:393-5. 